\title{
Fumonisinas: efeitos toxicológicos, mecanismo de ação e biomarcadores para avaliação da exposição
}

\section{Fumonisins: toxicological effects, mechanism of action and biomarkers for exposure assesment}

\author{
Luciana Minami ${ }^{1}$; Paula Garcia Meirelles ${ }^{2}$; \\ Elisa Yoko Hirooka ${ }^{3}$; Elisabete Yurie Sataque Ono ${ }^{4 *}$
}

Resumo

Fumonisinas são toxinas produzidas por Fusarium verticillioides Sacc. Niremberg (F. moniliforme Sheldon), patógeno primário de milho, que está implicado em inúmeras doenças animais, com ênfase em leucoencefalomalácia em eqüinos, edema pulmonar em suínos e carcinomas hepáticos e renais em ratos e camundongos. Em seres humanos, os estudos epidemiológicos têm associado o consumo de milho altamente contaminado com fumonisinas ao câncer esofágico em populações da China e África do Sul. Além disso, a contaminação de milho por Fusarium spp. causa perdas econômicas consideráveis em todo o mundo. Estruturalmente, a fumonisina $\mathrm{B}_{1}\left(\mathrm{FB}_{1}\right)$ assemelha-se às bases esfingóides, sendo a toxicidade e carcinogenicidade associada à capacidade de inibir a ceramida sintetase, uma enzima chave na via de biossíntese dos esfingolipídeos, causando acúmulo de esfinganina e depleção de esfingolipídeos complexos importantes nas funções celulares. Devido à ocorrência global, as fumonisinas têm sido alvo de intensas investigações na tentativa de desenvolver biomarcadores capazes de avaliar a exposição à $\mathrm{FB}_{1} \mathrm{e}$, estabelecer os níveis de contaminação que não causem danos à saúde humana e animal. Esta revisão apresenta os principais aspectos referentes à toxicidade de fumonisinas em animais e sistemas in vitro, aliado ao mecanismo de ação bioquímica e aos biomarcadores visando avaliação da exposição. Palavras-chave: Fumonisinas, esfingolipídios, Fusarium verticillioides, biomarcadores, milho.

\begin{abstract}
Fumonisins, mycotoxins produced by Fusarium verticillioides Sacc. Niremberg (F. moniliforme Sheldon), the prevalent seed borne fungus of corn (Zea mays), have been associated with several animal diseases, such as equine leukoencephalomalacia, porcine pulmonary edema and hepatic and renal carcinomas in rats and mice. Epidemiological studies have linked consumption of fumonisin-contaminated corn with esophageal cancer in human populations in China and South Africa. In addition, fungal growth and further corn contamination by fumonisins cause great economic losses throughout the world. The
\end{abstract}

1 Farmacêutica formada pela Universidade Estadual de Londrina, Especialista em Análises Clínicas pela Universidade Estadual de Londrina.

2 Bacharel em Ciências Biológicas pela Universidade Estadual de Londrina, Mestranda do Programa de Pós-graduação em Biotecnologia do Departamento de Bioquímica e Biotecnologia da Universidade Estadual de Londrina.

3 Docente do Programa de Pós-graduação em Ciência de Alimentos - Departamento de Tecnologia de Alimentos e Medicamentos/ CCA/UEL.E-mail: hirooka@uel.br.

4 Docente do Programa de Mestrado em Biotecnologia do Departamento de Bioquímica e Biotecnologia/CCE/ UEL. E-mail: eysono@uel.br-Campus Universitário, Londrina-PR.

* Autor para correspondência. 
fumonisin $\mathrm{B}_{1}$ molecule bears remarkable structural resemblance to the long-chain base backbones of sphingolipids. The toxicity and carcinogenicity of $\mathrm{FB}_{1}$ is based on its ability to inhibit ceramide synthase, a key enzyme in the metabolism of complex sphingolipids. Inhibition of these metabolic pathway results in increased intracellular concentrations of free sphinganine and depletion of complex sphingolipids, which play important roles in cell regulation. Due to the worldwide occurrence of fumonisins in corn and corn-based products, many studies have aimed the development of biomarkers for exposure assessment and for establishment of acceptable exposure levels to fumonisins. This review discusses the toxicological effects of fumonisins in vivo and in vitro, biochemical mechanisms of action and the progress in development of biomarkers for exposure assessment.

Key words: Fumonisins, sphingolipids, Fusarium verticillioides, biomarkers, corn.

\section{Introdução}

O milho é o cereal mais cultivado no mundo, estando a produção anual em torno de quinhentos milhões de toneladas (DOWSWELL; PALIWAL; CANTRELL, 1996). O Brasil é o terceiro produtor mundial de milho, com uma produção anual de 42,3 milhões de toneladas (ton), sendo o Estado do Paraná responsável por $26 \%$ da produção nacional e cerca de $80 \%$ das exportações de milho no Brasil (DUARTE, 2003).

O milho apresenta uma grande importância sócioeconômica por constituir um ingrediente essencial da dieta, participando em mais de 500 produtos alimentícios (MELO FILHO; RICHIETTI, 1997). Cerca de $66 \%$ da produção mundial destina-se à alimentação animal, $20 \%$ ao consumo humano direto e $8 \%$ à indústria, e o restante $(6 \%)$ constitui a somatória de perdas e produção de sementes (DOWSWELL; PALIWAL; CANTRELL, 1996). No Brasil, a maior parcela (60 a $80 \%$ ) do milho produzido é destinada à formulação de ração para a suinocultura e avicultura, na forma de matéria-prima básica (PEDROSA; DEZEN, 1991).

A alta qualidade nutricional expõe o milho à contaminação por microrganismos, principalmente fungos micotoxigênicos como $F$. verticillioides (SYDENHAM; SHEPARD, 1996), que tem sido alvo de intensa investigação devido à elevada freqüência em milho e derivados (MUNKVOLD; DESJARDINS, 1997).

A ocorrência natural de micotoxinas em cereais, além dos problemas de saúde, pode ter implicações econômicas importantes para diversos setores comerciais, incluindo produtores de grãos, criadores de animais, assim como processadores de alimentos e rações (PETSKA; ABOUZEID; SUTKINO, 1995).

As fumonisinas, compostos metabólicos secundários produzidos por $F$. verticillioides e $F$. proliferatum, constituem um grupo de micotoxinas que contaminam o milho e seus derivados em nível mundial, inclusive em combinação com outras micotoxinas (TURNER; NIKIEMA; WILD, 1999). Quinze análogos de fumonisinas já foram identificados (WORLD HEALTH ORGANIZATION, 2000), embora as formas presentes em quantidades significativas como contaminantes naturais de milho e derivados sejam as fumonisinas $\mathrm{B}_{1}\left(\mathrm{FB}_{1}\right), \mathrm{B}_{2}\left(\mathrm{FB}_{2}\right)$ e $\mathrm{B}_{3}\left(\mathrm{FB}_{3}\right)$ (VISCONTI et al., 1995), sendo a FB a $_{1}$ mais abundante.

A alta incidência de fumonisinas em milho brasileiro é preocupante, uma vez que um dos primeiros estudos revelou 100 e $97,4 \%$ de contaminação por fumonisina $\mathrm{B}_{1}\left(\mathrm{FB}_{1}\right)$ e $\mathrm{B}_{2}\left(\mathrm{FB}_{2}\right)$, respectivamente (HIROOKA et al., 1996).

As fumonisinas podem causar prejuízos econômicos na criação de eqüinos, suínos e aves. Uma das manifestações mais graves em animais causadas pelo consumo de milho contaminado é a leucoencefalomalácia eqüina (LEME), uma doença que geralmente resulta na morte dos animais dentro de poucas horas a uma semana. Em suínos, a ingestão de fumonisina causa a síndrome de edema pulmonar (PPE) e hidrotórax (MUNKVOLD; DESJARDINS, 1997). Em ratos, a FB 1 apresenta atividade hepatotóxica e hepatocarcinogênica. Estudos têm demonstrado que a exposição à $\mathrm{FB}_{1}$ 
resulta em nefrotoxicidade e hepatotoxicidade em todas as espécies animais estudadas (ratos, camundongos, coelhos, eqüinos, suínos e macacos), aliadas à hipercolesterolemia em determinadas espécies (suínos e macacos), incluindo alguns primatas (WORLD HEALTH ORGANIZATION, 2000).

Em seres humanos, os estudos epidemiológicos nas regiões de Transkei (África do Sul) e China central relacionaram o alto índice de câncer esofágico com a ingestão de milho altamente contaminado por fumonisinas (MUNKVOLD; DESJARDINS, 1997). Altos níveis de fumonisinas também têm sido associados com câncer hepático na China (UENO et al., 1997). A "International Agency for Research on Cancer" (IARC) classificou as toxinas derivadas de $F$. verticillioides como possivelmente carcinogênicas ao homem (Classe 2B) (VAN DER WESTHUIZEN et al., 1999).

As fumonisinas são estruturalmente semelhantes aos precursores dos esfingolipídeos, uma classe de lipídeos de membrana que apresentam importante papel na regulação celular. As fumonisinas inibem a enzima ceramida sintetase, uma enzima chave na biossíntese dos esfingolipídeos, levando ao acúmulo intracelular do precursor esfinganina (Sa) e diminuição da esfingosina (So) (TURNER; NIKIEMA; WILD, 1999). A redução dos esfingolipídeos complexos e o acúmulo de intermediários bioativos têm importante papel não só para explicar a toxicidade da $\mathrm{FB}_{1}$, mas também alterações de outras funções celulares importantes. Estes incluem o controle e integridade da membrana, proliferação celular, diferenciação e apoptose (FINK-GREMMELS, 1999; TURNER; NIKIEMA; WILD, 1999).

Considerando a elevada contaminação de milho por $F$. verticillioides e fumonisinas, aliada aos sérios riscos causados à saúde humana e animal, a avaliação da exposição a fumonisinas é imprescindível para implantar uma proposta de concentração máxima a ser tolerada durante o controle de qualidade de produtos destinados ao consumo humano e animal.
Assim, o desenvolvimento de biomarcadores e sua aplicação em estudos epidemiológicos devem constituir uma prioridade na pesquisa destas toxinas. Esta revisão apresenta os principais aspectos relacionados aos efeitos toxicológicos, mecanismo de ação e biomarcadores para avaliação da exposição a fumonisinas.

\section{Micotoxinas}

Os fungos produzem inúmeros metabólitos secundários, muitos dos quais têm sido associados com a indução de efeitos tóxicos em animais e seres humanos. Micotoxina é um termo derivado do grego (Mikes $=$ fungo e Toxicum $=$ veneno $)$, empregado para descrever substâncias tóxicas formadas por fungos em diferentes etapas do desenvolvimento micelial (D'MELLO; MACDONALD, 1997).

A síntese de micotoxinas é determinado geneticamente e intimamente relacionado às vias metabólicas principais (aminoácidos e ácidos graxos). A produção de toxina e o grau de contaminação de alimentos e gêneros alimentícios são regulados por fatores ambientais, composição e textura do substrato, umidade e temperatura. As plantas são mais suscetíveis à invasão fúngica sob condições de estresse como seca ou excesso de irrigação, danos por insetos e exposição a pesticidas. Além disso, a suscetibilidade da planta determina as características do crescimento fúngico e a taxa de produção de toxinas (FINK-GREMMELS, 1999).

Até o momento foram identificadas mais de 300 micotoxinas que provocam sinais de toxicidade em espécies animais, cuja ocorrência global se destaca entre o fator de risco à saúde humana e animal (FINK-GREMMELS, 1999).

Os fungos toxigênicos podem produzir um ou mais destes metabólitos, que respondem por perdas anuais de milhões de dólares (HUSSEIN; BRASSEL, 2001). Tradicionalmente são divididos em dois grupos ecológicos - fungos de campo (ou patógenos/ endofíticos de plantas) e de armazenamento (ou 
saprofíticos) - de acordo com o requerimento de água (PLACINTA; D’MELLO; MACDONALD, 1999).

Em geral, as micotoxinas são classificadas baseando-se na espécie fúngica produtora, estrutura química e/ou modo de ação. Entretanto, deve-se ressaltar que uma espécie de fungo pode produzir uma ou mais micotoxinas, podendo uma micotoxina ser produzida por diferentes espécies FÚNGICAS (HUSSEIN; BRASSEL, 2001).

O impacto das micotoxinas sobre a saúde depende da quantidade total de micotoxina ingerida, toxicidade do composto, presença de outras micotoxinas, características individuais como o peso corporal e interferências da dieta. Das micotoxinas conhecidas, cerca de 20 ocorrem em gêneros alimentícios em freqüência e níveis significativos na segurança alimentar. Estas toxinas são produzidas por gêneros pertencentes a Aspergillus, Penicillium, Fusarium, Alternaria e Claviceps (STEYN, 1995).

As espécies de Fusarium sintetizam diversas micotoxinas (PLACINTA; D'MELLO; MACDONALD, 1999), sendo as mais importantes do ponto de vista de saúde animal e produtividade pertencentes à classe dos tricotecenos, zearalenona e fumonisinas (D'MELLO; PLACINTA; MACDONALD, 1999). Estes fungos são encontrados em cereais nas regiões temperadas a sub-tropicais da América, Europa e Ásia (CREPPY, 2002).

\section{Fumonisinas}

As fumonisinas, micotoxinas produzidas principalmente por $F$. verticillioides e $F$. proliferatum (CREPPY, 2002), foram descobertas em 1988 por meio de seu isolamento de culturas de $F$. verticillioides MRC 826 (GELDERBLOM et al., 1988).

F. verticillioides pode causar doença em todos os estágios do desenvolvimento da planta de milho, infectando raízes, colmo e espigas causando podridão, assim como a deterioração de grãos armazenados. Este fungo não é só o patógeno mais freqüente de milho, como também está entre os fungos mais comumente encontrados colonizando plantas assintomáticas (MUNKVOLD; DESJARDINS, 1997).

As fumonisinas não são destruídas pelo processamento comumente utilizado em alimentos. Conseqüentemente, ainda não há tecnologia disponível para assegurar que todos os alimentos e gêneros alimentícios estejam completamente isentos de fumonisinas (MUNKVOLD; DESJARDINS, 1997). Geralmente não há nenhuma diferença na aparência visual do milho com baixas ou altas concentrações de fumonisinas (SAUNDERS; MEREDITH; VOSS, 2001).

Fumonisina $\mathrm{B}_{1}$, o análogo mais abundantemente encontrado (GALVANO et al., 2002), tem a fórmula empírica $\mathrm{C}_{34} \mathrm{H}_{59} \mathrm{NO}_{15}$ e consiste de diéster de propano-1,2,3-ácido tricarbalílico e 2-amino-12,16dimetil-3,5,10,14,15-pentahidroxieicosano (Figura 1), sendo que os grupos hidroxila dos carbonos 14 e 15 encontram-se esterificados com o grupo carboxila terminal do ácido tricarbalílico (BEZUIDENHOUT et al., 1998). As quatro principais categorias, denominadas de fumonisina A, B, C e P, são compostos por $\mathrm{FA}_{1}, \mathrm{FA}_{2}, \mathrm{FA}_{3}, \mathrm{FAK}_{1} ; \mathrm{FB}_{1}, \mathrm{FB}_{2}, \mathrm{FB}_{3}$, $\mathrm{FB}_{4} ; \mathrm{FC}_{1}, \mathrm{FC}_{2}, \mathrm{FC}_{3}, \mathrm{FC}_{4} ; \mathrm{FP}_{1}, \mathrm{FP}_{2}$ e $\mathrm{FP}_{3}$ (MUSSER; PLATTNER, 1997). Além destes 15 análogos, existem outros metabólitos de menor importância não detectados como contaminantes naturais (WORLD HEALTH ORGANIZATION, 2000).

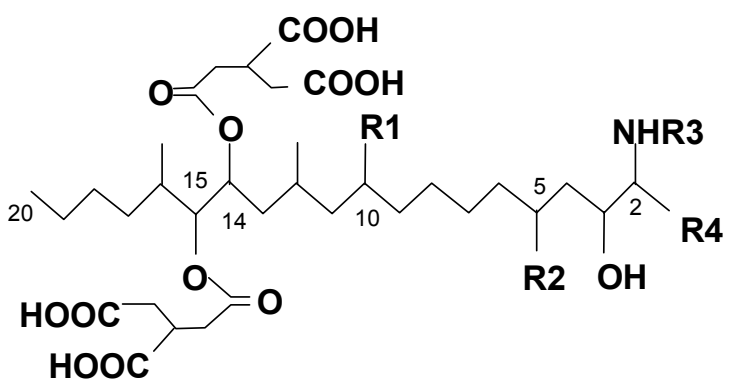

\begin{tabular}{l|cccc} 
& $\mathrm{R} 1$ & $\mathrm{R} 2$ & $\mathrm{R} 3$ & $\mathrm{R} 4$ \\
\hline $\mathrm{FB}_{1}$ & $\mathrm{OH}$ & $\mathrm{OH}$ & $\mathrm{H}$ & $\mathrm{CH}_{3}$ \\
$\mathrm{FB}_{2}$ & $\mathrm{H}$ & $\mathrm{OH}$ & $\mathrm{H}$ & $\mathrm{CH}_{3}$ \\
$\mathrm{FB}_{3}$ & $\mathrm{OH}$ & $\mathrm{H}$ & $\mathrm{H}$ & $\mathrm{CH}_{3}$
\end{tabular}

Figura 1. Estrutura química das fumonisinas $B_{1}, B_{2}$ e $B_{3}$. 
As fumonisinas causam um complexo conjunto de efeitos tóxicos em animais, como: leucoencefalomalácia, edema pulmonar, toxicidade renal e hepática, carcinogenicidade, imunossupressão (e algumas vezes imunoestimulação) e neurotoxicidade (DESAI et al., 2002).

\section{Toxicologia das Fumonisinas}

Os estudos sobre a toxicologia das fumonisinas estão dirigidos para $\mathrm{FB}_{1}$, o principal análogo produzido por $F$. verticillioides tanto em meios de cultura quanto em milho e produtos derivados naturalmente contaminados (UENO et al., 1993).

Estudos toxicocinéticos mostraram que as fumonisinas são muito pouco absorvidas no trato gastrintestinal, rapidamente eliminadas, ocorrendo pequeno acúmulo no fígado e rim (NORRED et al., 1996; VOSS et al., 2001). Após administração de uma única dose de $\mathrm{FB}_{1}(7,5 \mathrm{mg} / \mathrm{Kg})$ por via intraperitoneal em ratos, o tempo de concentração plasmática máxima foi de aproximadamente $20 \mathrm{~min}$ e o tempo de meia vida de eliminação sérica de aproximadamente $18 \mathrm{~min}$ (VOSS et al., 2001). Em macacos, estudos toxicocinéticos, demonstraram que a FB $\mathrm{F}_{1}$ tem baixa biodisponibilidade e uma curta meia vida de eliminação. De fato, os níveis séricos após uma dose oral atingem um máximo dentro de duas horas, diminuindo rapidamente em níveis abaixo do limite de detecção (VAN DER WESTHUIZEN; SHEPARD; VAN SCHALKWYK, 2001a).

O mecanismo de ação de fumonisinas não foi completamente elucidado, mas alguns modelos propostos explicam determinadas doenças causadas em animais. O bloqueio do metabolismo dos esfingolipídeos é o passo inicial ou o evento principal, intimamente relacionado com o início e progressão das doenças associadas com fumonisinas em eqüinos, suínos e roedores (RILEY et al., 2001). Também está associada com alterações na proliferação celular e morte celular em culturas de células primárias e algumas linhagens de células (BAILLY et al., 2001).
As fumonisinas apresentam semelhança estrutural com as bases esfingóides livres (RILEY et al., 1993), em particular a esfinganina ( $\mathrm{Sa}$ ) e esfingosina (So) (Figura 2), intermediários na biossíntese e degradação de outras bases esfingóides de cadeia longa e esfingolipídeos mais complexos (FINK-GREMMELS, 1999), bloqueando a biossíntese de novo dos esfingolipídeos, pela potente inibição de ceramida sintase [esfingosina (esfinganina)-N-acetiltransferase] (WANG et al., 1991), uma enzima chave na via de biossíntese de novo dos esfingolipídeos (RILEY et al., 1993). A ligação da $\mathrm{FB}_{1}$ ao sítio catalítico da ceramida sintase constitui o primeiro evento no processo de bloqueio do metabolismo lipídico (RILEY et al., 2001).

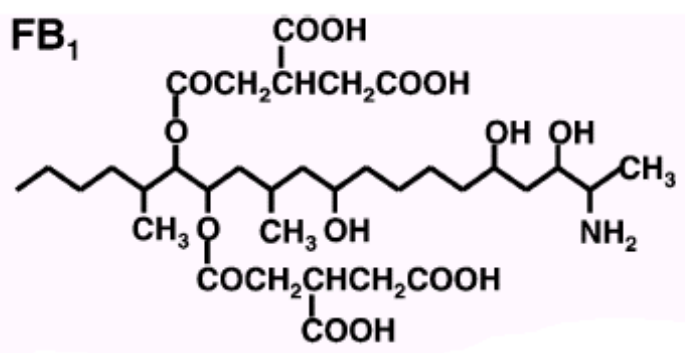

Esfingosina

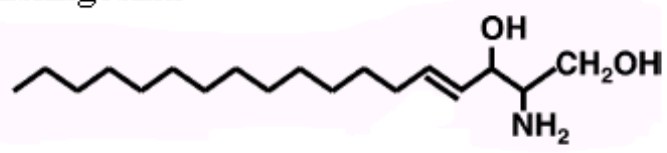

Esfinganina

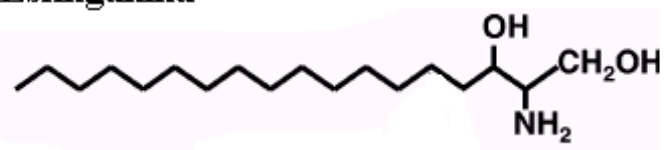

Figura 2. Estrutura da fumonisina $B_{1}$ e das bases esfingóides

A completa inibição da ceramida sintase causa uma elevação rápida da concentração intracelular de Sa (VAN DER WESTHUIZEN et al., 1999), e depleção dos esfingolipídeos complexos nas células (RILEY et al., 1993). Entretanto, a magnitude destas respostas depende de muitos fatores, como a taxa de turnover dos esfingolipídeos e crescimento celular (MERRIL JR. et al., 2001). 
As fumonisinas também atuam nos sítios de regulação celular, aparentemente independente do bloqueio do metabolismo dos esfingolipídeos, alterando a proliferação e a comunicação celular, adesão, apoptose, indução de estresse oxidativo e modulação de expressão gênica (MOBIO et al., 2000).

A administração de uma única dose de $25 \mathrm{mg}$ $\mathrm{FB}_{1} / \mathrm{kg}$ (alta) em camundongos causou um aumento dos níveis de esfinganina no fígado, intestino delgado e rins, enquanto a administração de uma dose de 0,03 $\mathrm{mg} \mathrm{FB}_{1} / \mathrm{Kg}$ (baixa) por 5 dias não teve efeito sobre as bases esfingóides nos rins. No entanto, a administração diária de baixas doses após uma única dose alta prolongou a elevação nos níveis de esfinganina renal em comparação aos camundongos que receberam uma única dose alta (ENONGENE et al., 2002).

O aumento prolongado de bases esfingóides livres em alguns tipos celulares pode ser devido a uma combinação da persistência da inibição da ceramida sintase, diferenças na cinética de biossíntese da $\mathrm{Sa}$ (atividade da serina palmitoiltransferase) e degradação (via esfinganina quinase) (ENONGENE et al., 2002).

O bloqueio do metabolismo de esfingolipídeos causado pelas fumonisinas pode responder por danos celulares de diversas maneiras, sendo necessário considerar as vias metabólicas paralelas que podem ser afetadas pela inibição da ceramida sintase, a potente bioatividade das bases esfingóides e seus metabólitos, e as múltiplas funções dos esfingolipídeos mais complexos (MERRIL JR. et al., 1997).

Baseados nos aspectos gerais da função dos esfingolipídeos dentro de uma célula, a redução dos esfingolipídeos complexos e o acúmulo de intermediários são responsáveis pela toxicidade e também pelo prejuízo de outras funções celulares essenciais (FINK-GREMMELS, 1999).

\section{Esfingolipídeos}

Os esfingolipídeos constituem uma classe de lipídeos de membrana que exercem importante papel na regulação celular (FERRANTE et al., 2002), encontrados em todas as células eucarióticas (MERRIL JR. et al., 1997). Estão localizados nas membranas celulares, lipoproteínas (especialmente as de baixa densidade) e outras estruturas ricas em lipídeos. Os esfingolipídeos são cruciais para a manutenção da estrutura lipoprotéica das membranas, comunicação celular, interação entre células e matriz extracelular, modulação dos receptores de fatores de crescimento e atuam como segundos mensageiros nas vias de sinalização, mediando o crescimento celular, diferenciação e morte celular (TURNER; NIKIEMA; WILD, 1999). Também servem como sítios de ligação para proteínas da matriz extracelular, inclusive para determinados microrganismos e toxinas microbianas (MERRIL JR. et al., 2001).

Apesar de terem sido descobertos há mais de 100 anos, apenas recentemente foram reconhecidos por sua importância na nutrição e como mediadores dos efeitos das micotoxinas, tais como as fumonisinas (ABNET et al., 2001b). O grupo consiste de substâncias com estrutura diversa formado por uma base esfingóide de cadeia longa e um grupo amino, freqüentemente substituído por um ácido graxo de cadeia longa (ABNET et al., 2001a).

A esfingosina (So) é a base esfingóide prevalente dos esfingolipídeos de mamíferos e algumas vezes é utilizado como um termo genérico para todas as bases esfingóides, contudo, a esfingosina mais freqüente refere-se especificamente à D-eritro-1,3-diidróxi-2amino-octadec-4-eno ou 4-trans-esfinganina. As bases esfingóides variam no comprimento da cadeia alquila, posição da dupla ligação (e número de duplas ligações), e outros grupos funcionais tais como uma hidroxila na posição 4. Os esfingolipídeos complexos apresentam um ácido graxo ligado numa ligação amida (formando ceramidas) e uma cabeça polar. Os ácidos graxos variam no comprimento da cadeia, grau de insaturação (maioria são insaturados) e a presença ou não de um grupo hidroxila no átomo de carbono $\alpha$ ou $\omega$ (MERRIL JR. et al., 2001). Atualmente há mais de 300 esfingolipídeos conhecidos com diferentes cabeças polares (MERRIL JR. et al., 1997). 
Na via de biossíntese dos esfingolipídeos, a ceramida sintase acila o grupo amino da esfinganina com um ácido graxo para produzir diidroceramida ( $\mathrm{N}$-acilesfinganina), que então é convertida em ceramida pela adição de uma dupla ligação 4,5-trans e finalmente em esfingolipídeos mais complexos, como as esfingomielinas e glicoesfingolipídeos, pela adição de grupos polares apropriados (KIM et al., 2001). A renovação destes esfingolipídeos leva à formação de esfingosina, que pode sofrer posterior catabolismo, ou pode ser re-acilado pela ceramida sintase para novamente produzir ceramida (Figura 3).

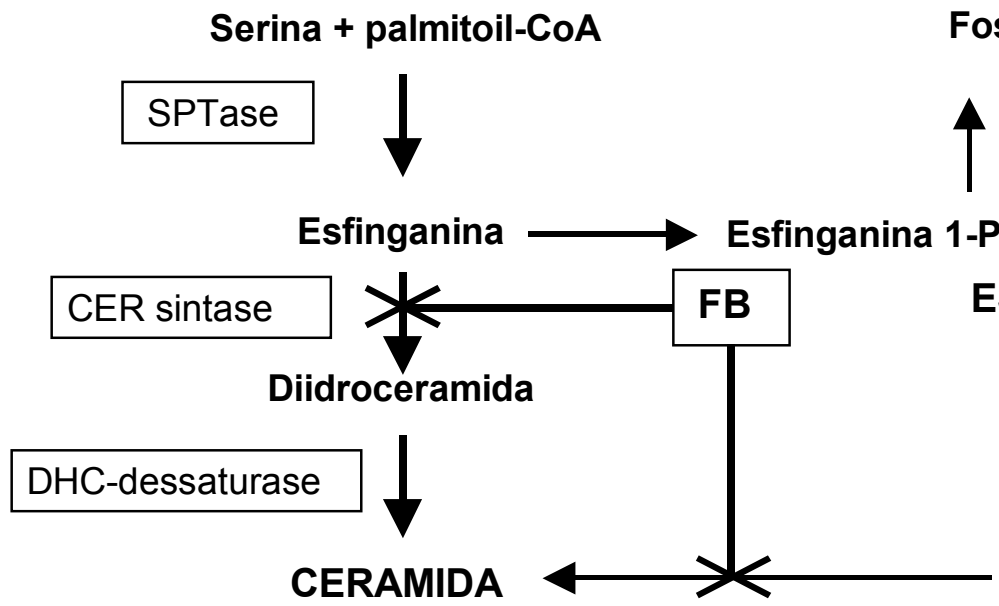

Fosfatidiletanolamina

CERAMIDA

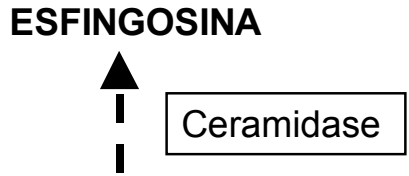

CERAMIDA

Figura 3. Locais de ação das fumonisinas (FB) no metabolismo de esfingolipídios (Figura reproduzida a partir do IPCS Environmental Health Criteria Document 219: Fumonisin $\mathrm{B}_{1}$, com permissão). Abreviaturas: SPTase (serina palmitoiltransferase, CER sintase (ceramida sintase), DHC-dessaturase (diidroceramida dessaturase), So-kinase e -liase (esfingosina quinase e liase)

Os esfingolipídeos complexos atuando como precursores de segundos mensageiros que modulam as respostas celulares aos fatores de crescimento, citocinas, fatores de diferenciação e diversos agonistas do crescimento, ativam uma cascata de enzimas que hidrolisam a esfingomielina em ceramida (esfingomielinases), ceramida em esfingosina 1fosfato (esfingosina quinase). Cada um destes intermediários constitui um composto bioativo que pode afetar proteínas quinases, fosfoproteínas fosfatases e outras vias regulatórias nas células (MERRIL JR. et al., 2001).

Os intermediários na biossíntese de novo dos esfingolipídeos também são compostos altamente bioativos, sendo mantidos em baixas concentrações sob condições normais (MERRIL JR. et al., 2001). $\mathrm{Sa}$ e So estão normalmente presentes em concentrações mínimas nos tecidos, porém o nível de Sa livre é sempre menor que o de So livre (RILEY et al., 1993).

A inibição da ceramida sintase resulta em um aumento dos níveis de Sa nas células, e algumas vezes de níveis de So (SOLFRIZZO et al., 2001), resultando na elevação da relação Sa:So, tanto no sangue quanto na urina de ratos, camundongos, coelhos, porcos, pôneis, visões, macacos e parece ser o indicador mais sensível de exposição a fumonisinas (VAN DER WESTHUIZEN et al., 1999).

$\mathrm{O}$ acúmulo de Sa sintetizada de novo é um marcador bioquímico precoce em resposta ao 
tratamento com $\mathrm{FB}_{1}$ em doses abaixo daquelas que produzem evidências morfológicas de lesão (1mg/ $\mathrm{Kg}$ ), sendo que o aumento de Sa livre nos tecidos ocorre antes de danos evidentes serem detectados nos órgãos alvo (HE; BHANDARI; SHARMA, 2002). Em hepatócitos tratados com $\mathrm{FB}_{1}$, uma parte de Sa acumulada é metabolizada a esfinganina 1fosfato seguida de clivagem a aldeído graxo e fosfato de etanolamina, e ambos, podem ser redirecionados a outras vias metabólicas. A capacidade das células de metabolizar rapidamente as bases esfingóides livres a produtos menos bioativos podem protegê-las das toxicidades, associadas tanto com a elevação das bases esfingóides livres quanto das ceramidas (RILEY et al., 2001).

Além do acúmulo de Sa livre, a inibição da ceramida sintase altera outros lipídeos com importantes funções celulares (MERRIL JR. et al., 2001). A exposição a fumonisinas leva a um desequilíbrio no metabolismo dos fosfoglicerolipídeos e dos ácidos graxos, alteração da expressão de citocinas como fator de necrose tumoral (TNF- $\alpha$ )

\section{Fator de Necrose Tumoral - $\alpha$}

O fator de necrose tumoral - $\alpha$ (TNF- $\alpha$ ), assim como os esfingolipídeos, estão envolvidos na regulação da apoptose e replicação celular. O TNF- $\alpha$ é uma importante citocina envolvida na regulação da apoptose, reestruturação dos tecidos e processos inflamatórios (HE; RILEY; SHARMA, 2001). Uma vez que o TNF- $\alpha$ se liga aos receptores, uma seqüência de eventos complexos e sinalizadores interrelacionados ocorrem nas células, sejam de natureza pró-apoptótica ou anti-apoptóticas. Dentre estes eventos está a ativação de esfingomielinases, mediando a produção de ceramida, ativação da caspase, expressão de proteínas inibidoras da apoptose e ativação do fator nuclear $\kappa \mathrm{B}(\mathrm{NF \kappa B})$. É possível deste modo que as vias dependentes dos esfingolipídeos e TNF- $\alpha$ interajam para influenciar a toxicidade da $\mathrm{FB}_{1}$ (VOSS et al., 2002).
Em suínos, os estudos evidenciaram que o TNF$\alpha$ pode exercer um papel primário na patofisiologia da falência cardíaca. Muitos dos sintomas clínicos da falência cardíaca, incluindo disfunção do ventrículo esquerdo, edema pulmonar, podem ser explicados pelos efeitos biológicos conhecidos do TNF- $\alpha$, como os efeitos inotrópicos no coração. Tanto o acúmulo de bases esfingóides livres, quanto a expressão de TNF- $\alpha$ no coração após exposição à $\mathrm{FB}_{1}$, podem ser responsáveis pela disfunção cardíaca relatada nos suínos (HE; BHANDARI; SHARMA, 2002).

\section{Toxicidade das Fumonisinas em Animais}

Embora as fumonisinas tenham sido descobertas em 1988, a toxicidade do milho contaminado por $F$. verticillioides denominada de "envenenamento por milho mofado" foi documentada há mais de um século em eqüinos e, descrita pela primeira vez em 1850 nos Estados Unidos (MUNKVOLD; DESJARDINS, 1997).

A manifestação mais grave de envenenamento por milho mofado é a leucoencefalomalácia (LEM), uma doença cerebral fatal de cavalos, burros, mulas e coelhos (MUNKVOLD; DESJARDINS, 1997). Os sintomas da LEM incluem ataxia, parestesia, apatia, hipersensibilidade, debilidade da função motora, necrose da substância branca cerebral e lesões no córtex cerebral (HUSSEIN; BRASSEL, 2001), resultando em morte dentro de poucas horas a uma semana (NORRED; VOSS, 1994). Além de lesões cerebrais, foram relatadas anormalidades histopatológicas no fígado e rim em cavalos que ingeriram fumonisina pura, milho naturalmente contaminado ou material de cultura de $F$. verticillioides (WANG et al., 1991).

Em suínos, o principal sintoma de toxicidade das fumonisinas foi denominado de edema pulmonar (PPE) (HASCHEK et al., 2001), após a eclosão de uma doença fatal em suínos que consumiram milho contaminado com $F$. verticillioides provenientes da safra de grãos de 1989 em Iowa, Illinois e Georgia 
nos Estados Unidos (MARASAS, 2001). A doença tem sido reproduzida experimentalmente pelo fornecimento de grãos contaminados com $F$. verticillioides, material de cultura e pela administração intravenosa de $\mathrm{FB}_{1}$ pura (HASCHEK et al., 2001). A patogênese do edema pulmonar se deve a danos ao endotélio pulmonar, danos ao epitélio alveolar e falência cardíaca (GUMPRECHT et al., 2001), conduzindo a óbito dentro de 4-7 dias de ingestão diária de fumonisinas em concentrações maiores ou iguais a $92 \mu \mathrm{g} / \mathrm{g}$ ou $6 \mathrm{mg} / \mathrm{Kg}$ de peso corporal/dia (HASCHEK et al., 2001). A elevação do colesterol sérico parece ser uma característica constante da condição e enzimas hepáticas também podem estar aumentadas (D'MELLO, PLACINTA; MacDONALD, 1999). Além disso, observam-se alterações nos sistemas hepático, cardiovascular e imune (HASCHEK et al., 2001).

Em ensaios com animais, o fígado e o rim são os órgãos alvo principais (VOSS et al., 2001). Resultados de dois anos de bioensaios mostraram claramente a carcinogenicidade da $\mathrm{FB}_{1}$ em roedores. Adenomas e carcinomas no túbulo renal foram induzidos em ratos machos tratados com dietas contendo 50 ou $150 \mathrm{ppm}$ de $\mathrm{FB}_{1}$, assim como adenomas e carcinomas hepáticos em camundongos fêmeas (VOSS et al., 2002).

Em aves, os efeitos adversos caracterizam-se pela redução no desenvolvimento, problemas cardíacos, imunossupressão, degeneração e necrose hepática (NORRED; VOSS, 1994). Amostras de milho contaminado com fumonisinas foram implicadas em síndrome de mortalidade aguda em frangos de corte com 10 a 16 dias de idade (D'MELLO; PLACINTA; MACDONALD, 1999). Embora os patos pareçam ser resistentes à toxicidade da $\mathrm{FB}_{1}$ em termos de mortalidade, foi observada hepatotoxicidade administrando $5 \mathrm{mg} / \mathrm{Kg}$ /dia por um período de 12 dias (BAILLY et al., 2001).

$\mathrm{A} \mathrm{FB}_{1}$ não atravessa a placenta, nem apresentou efeitos teratogênicos em ratos, camundongos ou coelhos, mas altas doses tóxicas maternas foram embriotóxicas (VOSS et al., 2001). Estudos de Collins et al. (1998) mostraram que doses de $25 \mathrm{mg} / \mathrm{Kg}$ de $\mathrm{FB}_{1}$ ou mais em ratas prenhas provocaram aumento na reabsorção óssea e aumento da variação da calcificação, assim como severa toxicidade materna e retardamento no desenvolvimento fetal com doses de $50 \mathrm{mg} / \mathrm{Kg}$.

Estudos comparativos da toxicidade das fumonisinas em diferentes animais levaram a concluir que o principal órgão alvo difere em cada espécie, contudo certos órgãos, incluindo o fígado e o rim, parecem ser afetados de forma constante em maior ou menor extensão, sendo hepatotóxica em todos os animais testados (ratos, camundongos, coelhos, macacos, porcos e cavalos) e nefrotóxica em ratos, coelhos, porcos e camundongos (ENONGENE et al., 2000).

A toxicidade induzida pela $\mathrm{FB}_{1}$ no fígado parece exercer um papel importante durante a iniciação do câncer, sendo a indução de danos oxidativos e a peroxidação lipídica eventos iniciais importantes (GELDERBLOM et al., 2001).

Em seres humanos, os estudos epidemiológicos relacionaram os altos índices de câncer esofágico em populações consumindo milho com altos níveis de fumonisinas, na região de Transkei da província de Eastern Cape, África do Sul. A alta prevalência de câncer esofágico também ocorreu em KwazuluNatal, província da África do Sul e no distrito de Bomet do Kenya, embora não haja dados disponíveis sobre os níveis de fumonisinas nestas áreas. Altos níveis de fumonisinas também têm sido correlacionados com a alta incidência de câncer esofágico em Cixian e Linxian, municípios da República da China (VAN DER WESTHUIZEN et al., 1999). Ueno et al. (1997) apontaram as fumonisinas como um dos fatores de risco na promoção de câncer hepático primário, baseado num levantamento epidemiológico de 3 anos consecutivos em 120 amostras de milho das regiões de Haimen e Penlai, áreas de alto e baixo índice de câncer hepático primário na China, respectivamente (CARLSON et al., 2001). 


\section{Toxicidade em Sistemas in vitro}

Citotoxicidade, inibição de crescimento e indução de apoptose têm sido relatadas em linhagens de células e tecidos animais expostos à $\mathrm{FB}_{1}$ (SCHMELZ et al., 1998). Estudos realizados com macrófagos mostraram que a $\mathrm{FB}_{1}$ altera a função da membrana celular e o empacotamento dos lipídeos. Além de alterar a estrutura das membranas celulares, as fumonisinas promovem a produção de radicais livres e aceleram a reação em cadeia associada com a peroxidação lipídica (FERRANTE et al., 2002; YIN et al., 1998).

Em linhagens de células epiteliais renais (LLC$\mathrm{PK}_{1}$ ), o acúmulo de Sa provocado pela $\mathrm{FB}_{1}$ tem mostrado forte associação com a inibição do crescimento celular, alterações morfológicas e morte celular. A FB bloqueia o metabolismo dos esfingolipídeos e causa apoptose por uma via que envolve o acúmulo inicial de $\mathrm{Sa}$, que em seguida, estimula a indução da calmodulina (KIM et al., 2001).

Estudos com células epiteliais renais de suínos, células de cólon e queratinócitos humanos mostraram que a indução de apoptose, necrose e inibição da proliferação celular pela $\mathrm{FB}_{1}$ são $\mathrm{Sa}$ dependentes (HE; BHANDARI; SHARMA, 2002). Em neurônios do hipocampo, a inibição da biossíntese de esfingolipídeos tem sido relacionado com diminuição do crescimento axonal (PELAGALLI et al., 1999). Em linhagens de células do epitélio do cólon humano (células HT29), a toxicidade da $\mathrm{FB}_{1}$ pode envolver a depleção dos esfingolipídeos complexos, provavelmente por alterar as interações célula-célula e célula-matriz extracelular, conhecidos por induzir apoptose nas células epiteliais (SCHMELZ et al., 1998).

\section{Fumonisinas e Carcinogenicidade}

As taxas de proliferação e morte celular juntamente com o estado de diferenciação dos tecidos estão entre os muitos fatores que contribuem para a carcinogenicidade. O principal efeito biológico da $\mathrm{FB}_{1}$ é a indução de apoptose em vários modelos de sistemas in vitro e in vivo. A apoptose é um processo especializado de morte celular sendo parte do desenvolvimento normal dos órgãos e manutenção tecidual, mas também pode ocorrer em resposta a vários estímulos ambientais e pode ser indicativo de toxicidade. Numerosas proteínas e outros constituintes celulares estão envolvidos nos processos apoptóticos e sua regulação, incluindo os esfingolipídeos e outros lipídeos afetados pela $\mathrm{FB}_{1}$ (DRAGAN et al., 2001).

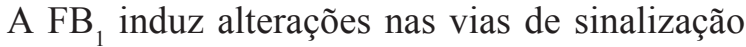
dos esfingolipídeos, levando a alterações nas relações entre morte e regeneração celular. Considerando que o aumento na concentração de ceramida é um importante sinal na indução de morte celular, a inibição da ceramida sintase pelas fumonisinas pode inibir a morte celular em curto prazo, ao passo que a inibição prolongada pode promover a morte celular induzida pelas bases esfingóides livres, se essas bases se acumularem em concentrações tóxicas (RILEY et al., 2001).

Numerosas vias regulatórias que envolvem os esfingolipídeos e influenciam os processos apoptóticos foram identificados (MERRIL JR. et al., 1997). O controle da apoptose é um processo complexo, não linear, que é célula específico e dependente de uma variedade de mecanismos de retroalimentação (RILEY et al., 2001). Teoricamente, em qualquer tempo específico o balanço entre a concentração intracelular de esfingolipídeos, efetores que protegem as células da apoptose (diminuição da ceramida, aumento da esfinganina 1-fosfato) e a concentração de efetores que induzem a apoptose (aumento da ceramida, bases esfingóides livres, ácidos graxos ou especificamente glicoesfingolipídeos), determinarão a resposta celular (RILEY et al., 2001).

O câncer é resultado de múltiplas alterações genéticas causadas por mutações herdadas nas células germinativas ou por mutações nas células somáticas, resultando em alteração do crescimento. Deste modo, apesar do extenso e eficiente 
mecanismo de reparo celular do DNA, como o DNA está replicando o tempo todo, há um potencial de ocorrer um erro que pode não ser reparado. Estes erros são raros, mas se ocorrerem em um gene envolvido no processo carcinogênico, constituem o primeiro passo à formação do câncer (DRAGAN et al., 2001).

Um agente pode aumentar o risco de câncer por causar danos diretos ao DNA, aumentar o número de replicações do DNA, ou ainda pela combinação de ambos os processos. O agente, ou um metabólito, capaz de formar um aduto mutagênico e provocar danos ao DNA, é comumente referido como genotóxico (DNA-reativo), enquanto que agentes capazes de potencializar a carcinogenicidade devido ao aumento do número de replicações do DNA constituem carcinógenos não-mutagênicos (DRAGAN et al., 2001).

A morte celular e a regeneração compensatória têm sido estabelecidas como o mecanismo de ação de uma variedade de carcinógenos químicos nãogenotóxicos, dentre elas as fumonisinas. Diversos estudos indicam que as fumonisinas não são genotóxicas e não reagem com o DNA. Além disto, a molécula da $\mathrm{FB}_{1}$ não possui grupos funcionais que sugiram reatividade direta com o DNA (DRAGAN et al., 2001).

Embora limitadas, existem evidências que a $\mathrm{FB}_{1}$ possa produzir danos ao DNA indiretamente pela produção de danos celulares oxidativos (YIN et al., 1998). O aumento da peroxidação lipídica ocorreu no fígado de ratos tratados com $\mathrm{FB}_{1}$ e em hepatócitos primários. Entretanto, algumas descobertas sugerem que danos celulares oxidativos podem ser devido à toxicidade e não pelo efeito celular químico direto (DRAGAN et al., 2001).

Galvano et al. (2002) mostraram que o tratamento com $\mathrm{FB}_{1}$ induz danos ao DNA de fibroblastos humanos, quando as células são expostas a altas concentrações desta micotoxina e por períodos prolongados. Estes danos parecem ser de caráter apoptótico, sendo precedido de um aumento da atividade da caspase-3, assim como no nível de fragmentação da PARP [poli-ADP-(ribose)polimerase] (GALVANO et al., 2002).

A capacidade da $\mathrm{FB}_{1}$ em induzir a apoptose seletivamente ou interromper o ciclo celular normal (HUSSEIN; BRASSEL, 2001) sugerem que a exposição crônica a baixos níveis de $\mathrm{FB}_{1}$ pode selecionar células com alteração nas propriedades de crescimento e, deste modo ser um cofator na carcinogênese (CIACCI-ZANELLA; JONES, 1999).

$\mathrm{O}$ risco de carcinogenicidade das fumonisinas pode ser relacionado a: (i) sua capacidade de aumentar as chances de sobrevivência de células que tenham DNA danificado por outros meios; (ii) estimulação direta da divisão celular; (iii) aumento da regeneração em resposta à morte celular (via bases esfingóides ou depleção de esfingolipídeos complexos); ou (iv) maior possibilidade de sobrevivência das células com DNA defeituoso pela falta de sensibilidade aos efeitos apoptóticos do bloqueio do metabolismo dos esfingolipídeos (RILEY et al., 2001).

Com base nos resultados de vários estudos, a "International Agency for Research on Cancer" (IARC) em Lyon, França, classificou as toxinas produzidas por $F$. verticillioides como carcinógenos do grupo 2B (isto é, possivelmente carcinogênico para humanos) em 1993 (WORLD HEALTH ORGANIZATION, 2000).

\section{Biomarcadores}

A análise de biomarcadores adequados aos fluidos biológicos é uma ferramenta útil para avaliar a exposição humana e animal às micotoxinas (SOLFRIZZO; AVANTAGGIATO; VISCONTI, 1997). Atualmente, dois biomarcadores de exposição estão sendo avaliados para fumonisinas, a saber, fumonisina na urina e no cabelo (SEWRAN et al., 2001) e a alteração da relação Sa:So na urina e no sangue (TURNER, NIKIEMA; WILD, 1999; MARASAS, 2001). 


\section{Fumonisina Livre}

A determinação direta de fumonisinas nos fluidos biológicos não constitui um bom indicador do seu consumo, visto que estas micotoxinas são rapidamente eliminadas após ingestão (SOLFRIZZO, AVANTAGGIATO; VISCONTI, 1997). Dados toxicocinéticos têm mostrado que a $\mathrm{FB}_{1}$ é eliminada dentro de poucas horas do soro de macacos, seguida de administração oral ou intravenosa (VAN DER WESTHUIZEN; SHEPARD; VAN SCHALKWYK, 2001a). De fato, os níveis séricos após uma dose oral atingem um máximo dentro de duas horas, diminuindo rapidamente a níveis abaixo do limite de detecção. Esta rápida eliminação, assim como a baixa biodisponibilidade e a falta de um metabólito principal inferem que a determinação direta de $\mathrm{FB}_{1}$ pode não ser praticável como um biomarcador de exposição (VAN DER WESTHUIZEN; SHEPARD; VAN SCHALKWYK, 2001b).

A análise da urina é a mais indicada para determinar a fumonisina livre em populações altamente expostas. Entretanto, a determinação de fumonisina urinária não é possível com as metodologias atuais em áreas com baixos níveis de contaminação ou baixo consumo de milho (TURNER; NIKIEMA; WILD, 1999).

Sewran et al. (2001) indicaram que as $\mathrm{FB}_{1}, \mathrm{FB}_{2}$ e $\mathrm{FB}_{3}$, assim como os aminopolióis $\mathrm{AP}_{1}$ e $\mathrm{AP}_{2}$, acumulam-se na queratina da matriz capilar, podendo prover um sistema facilmente aplicável para avaliar a exposição crônica a fumonisinas.

\section{Relação Sa:So}

O emprego da relação Sa:So como um biomarcador de exposição a fumonisinas foi proposto por Riley et al. (1993), sendo a sensibilidade demonstrada em diferentes espécies animais incluindo ratos, cavalos, porcos, aves, lampréias e coelhos (SOLFRIZZO; AVANTAGGIATO; VISCONTI, 1997).
A inibição da ceramida sintase pela fumonisina resulta no aumento intracelular da concentração de Sa em relação à concentração de So, nos tecidos, urina e sangue de ratos, coelhos, porcos, pôneis, patos, visões e macacos (RILEY et al., 1993; SHEPARD et al., 1996; VAN DER WESTHUIZEN et al., 1999; BAILLY et al., 2001; ENONGENE et al., 2000). O aumento da relação Sa:So ocorre pelo menos 42 dias antes de qualquer outro indicador bioquímico sérico de lesão celular (MERRIL JR. et al., 1997).

Este biomarcador é particularmente importante por ser um indicativo tanto da exposição como de efeitos tóxicos derivados das alterações bioquímicas produzidas diretamente pela exposição a fumonisinas em animais (SOLFRIZZO et al., 2001). A elevação da relação Sa:So parece ser sensível e específica pois a inibição da $\mathrm{N}$-acetiltransferase nos hepatócitos de ratos parece ser altamente específica; a relação no soro está elevada em todos os animais tratados com $\mathrm{FB}_{1}$ pura; relações elevadas são observadas em tecidos aparentemente normais; a relação sérica começa a se elevar antes de qualquer outra alteração bioquímica no soro (RILEY et al., 1993; TURNER; NIKIEMA; WILD, 1999; VAN DER WESTHUIZEN et al., 1999).

O biomarcador tem sido validado baseado na elevação consistente da relação $\mathrm{Sa}$ :So em suínos e ratos, quanto à dose e o tempo de exposição a fumonisinas na dieta (SOLFRIZZO et al., 2001). Em populações não expostas a fumonisinas, a utilização da relação ainda aguarda validação (TURNER, NIKIEMA; WILD, 1999).

A urina também pode proporcionar uma matriz para o bio-monitoramento da relação Sa:So (TURNER; NIKIEMA; WILD, 1999). Entretanto, um problema encontrado é o nível extremamente baixo das bases esfingóides na urina de seres humanos do sexo masculino, tornando-se necessário a utilização de grandes volumes de urina (CASTEGNARO et al., 1998; VAN DER WESTHUIZEN et al., 1999).

Os métodos para analisar as bases esfingóides 
envolvem numerosos passos e são extremamente demorados. Um dos pré-requisitos para o estudo de um biomarcador de larga escala é a facilidade e rapidez das determinações e repetições (TURNER; NIKIEMA; WILD, 1999). Uma validação completa dos níveis de bases esfingóides séricas e urinárias como biomarcadores de exposição humana a fumonisinas constitui prioridade no desenvolvimento de estudos para determinar se as fumonisinas são agentes etiológicos na promoção do câncer esofágico (ABNET et al., 2001a).

\section{Considerações Finais}

Devido à prevalência de $F$. verticillioides em milho, as fumonisinas ocorrem potencialmente em qualquer lugar onde o milho se desenvolva, e podem freqüentemente contaminar produtos derivados de milho. A ingestão constante de fumonisinas é preocupante devido à comprovação de efeito tumoral e carcinogênico em ratos, além da recente associação com o câncer esofágico e câncer hepático primário.

Um grande número de estudos nos últimos 10 anos relataram a ocorrência de altos níveis de fumonisinas tanto em países em desenvolvimento quanto em países desenvolvidos, não havendo dúvidas sobre a exposição universal de indivíduos consumidores de milho e produtos derivados. Os níveis de exposição variam amplamente conforme o nível de contaminação dos alimentos, grau de processamento e porcentagem da dieta baseada em milho.

$\mathrm{O}$ "Mycotoxin Committee of the American Association of Veterinary Laboratory Diagnosticians (MCAAVLD)" tem recomendado níveis de exposição máxima a fumonisinas visando reduzir as toxicoses animais e prevenir a exposição humana. Estes incluem: $<5$ ppm para eqüinos, $<10$ ppm para suínos, $<50$ ppm para aves e bovinos de corte.

Uma importante questão em relação à exposição humana é a estabilidade das fumonisinas à secagem e ao processamento de milho.
Embora o impacto das fumonisinas na saúde humana ainda não esteja totalmente elucidado, os relatos têm correlacionado o consumo de milho contaminado com $F$. verticillioides aos altos índices de câncer esofágico na África do Sul e na China, implicando as fumonisinas na etiologia desta doença. Todavia não se deve descartar a presença de outros fatores associados com a indução de câncer, confundindo os resultados. Salienta-se que os efeitos tóxicos das fumonisinas baseiam-se principalmente em modelos experimentais, portanto a extrapolação para os seres humanos deve ser feita com cautela.

A dificuldade na extrapolação para seres humanos é explicada pela falta de dados adequados sobre o consumo alimentar, a falta de conhecimento sobre o risco relativo à saúde associado com os limites propostos especificamente, além da possibilidade de sinergismo com outras micotoxinas presentes no mesmo gênero alimentício. A interpretação dos parâmetros de avaliação de risco é complicada, uma vez que o perfil exato de ingestão de fumonisinas não foi estabelecido para determinar o "Provável Consumo Diário" (PDI) em seres humanos.

O papel preciso e o mecanismo de ação das fumonisinas em seres humanos ainda devem ser elucidados. Portanto, o desenvolvimento de biomarcadores capazes de avaliar a exposição humana possibilitaria estudos epidemiológicos, auxiliando no processo de determinação dos riscos à saúde, constituindo área prioritária nas pesquisas sobre fumonisinas.

A maioria dos estudos atuais utilizando culturas de células ou animais experimentais apresentaram uma boa correlação entre a exposição a fumonisinas e acúmulo de $\mathrm{Sa}$, freqüentemente expressa como relação Sa:So. In vivo, a situação pode ser mais complexa, uma vez que as bases esfingóides produzidas num tecido podem ser transportadas para outros (como fígado e rins). Outro fator complicador é a possibilidade de que outros componentes da dieta possam alterar a toxicidade das fumonisinas. Além disso, in vivo, as fumonisinas podem ter efeitos 
adicionais ao bloqueio do metabolismo dos esfingolipídeos. Entretanto, é provável que alterações diretas ou secundárias nas vias de sinalização celular envolvendo esfingolipídeos sejam as principais responsáveis pela toxicidade e carcinogenicidade.

O biomarcador em questão deve ser sensível para a exposição a fumonisinas, além de altamente específico. Apesar dos avanços nos métodos analíticos para determinar Sa e So, certos pontos chaves devem ser estudados para este biomarcador. Assim, a especificidade do biomarcador em relação a outras micotoxinas e fatores adicionais, constituídos de dieta ou infecções devem ser averiguados. A estabilidade da alteração da relação precisa ser determinada em populações humanas para permitir associações temporais entre a exposição, o biomarcador e a doença.

A relação Sa:So constitui um biomarcador altamente específico da exposição a fumonisinas, embora a utilização da relação Sa:So ainda aguarde validação nas populações não expostas.

A determinação de fumonisina livre no cabelo poderá constituir uma ferramenta na avaliação da exposição crônica a fumonisinas, possibilitando avaliar exposições passadas, podendo ser útil em estudos de prevalência nas populações consumindo milho contaminado. No entanto, são necessários estudos adicionais sobre a relação das fumonisinas e sua deposição no cabelo e estudos de toxicocinética e toxicodinâmica.

\section{Agradecimentos}

Os autores agradecem o apoio financeiro recebido pelo Conselho Nacional de Desenvolvimento Científico e Tecnológico (CNPq) e Fundação Araucária.

\section{Referências}

ABNET, C. C.; BORKOWF, C. B.; QIAO, Y.; ALBERT, P. S.; WANG, E.; MERRIL JR., A. H.; MARK, S. D.; DONG, Z.; TAYLOR, P. R.; DAWSEY, S. M. Sphingolipids as biomarkers of fumonisin exposure and risk of esophageal squamous cell carcinoma in China. Cancer Causes and Control, Dordrecht, v.12, p.821-828, 2001a.

ABNET, C. C.; BORKOWF, C. B.; QIAO, Y.; ALBERT, P. S.; WANG, E.; MERRIL JR., A. H.; MARK, S. D.; DONG, Z.; TAYLOR, P. R.; DAWSEY, S. M. A cross-sectional study of human serum sphingolipids, diet and physiologic parameters. Journal of Nutrition, Philadelphia, v.131, p.2748-2752, 2001b.

BAILLY, J. D.; BENARD, G.; JOUGLAR, J. Y.; DURAND, S.; GUERRE, P. Toxicity of Fusarium moniliforme culture material containing known levels of fumonisin $\mathrm{B}_{1}$ in ducks. Toxicology, Limerick, v.163, p.11-22, 2001.

BEZUIDENHOUT, S. C.; GELDERBLOM, W. C. A.; GORST-ALLMAN, C. P.; HORAK, R. M.; MARASAS, W. F. O.; SPITELLER, G.; VLEGGAAR, R. Structure elucidation of the fumonisins, mycotoxins from Fusarium moniliforme. Chemical Communication, Letchworth, p. 743-745, 1998.

CARLSON, D. B.; WILLIANS, D. E.; SPITSBERGEN, J. M.; ROSS, P. F.; BACON, C. W.; MEREDITH, F. I.; RILEY, R. T. Fumonisin $B_{1}$ promotes aflatoxin $B_{1}$ and $N$-methylN'-nitro-nitrosoguanidine-initiated liver tumors in rainbow trout. Toxicology and Applied Pharmacology, San Diego, v.172, p.29-36, 2001.

CASTEGNARO, M.; GARREN, L.; GALENDO, D.; GELDERBLOM, W.C. A.; CHELULE, P.; DUTTON, M. F.; WILD, C. P. Analytical method for determination of sphinganine and sphingosine in serum as a potencial biomarker for fumonisin exposure. Journal of Chromatography B, Amsterdam, v.720, p.15-24, 1998.

CIACCI-ZANELLA, J. R.; JONES, C. Fumonisin $\mathrm{B}_{1}$, a mycotoxin contaminat of cereal grains, and inducer of apoptosis via the tumour necrosis factor pathway and caspase activation. Food and Chemical Toxicology, Oxford, v.37, p.703-712, 1999.

COLLINS, T. F. X.; SHACKELFORD, M. E.; SPRANDO, R. L.; BLACK, T. N.; LABORDE, J. B.; HANSEN, D. K.; EPPLEY, R. M.; TRUCKSESS, M. W.; HOWARD, P. C.; BRYANT, M. A.; RUGGLES, D. I.; OLEJNIK, N.; RORIE, J. I. Effects of fumonisin $\mathrm{B}_{1}$ in pregnant rats. Part 2. Food and Chemical Toxicology, Oxford, v.36, p.673-685, 1998.

CREPPY, E. E. Update of survey, regulation and toxic effects of mycotoxins in Europe. Toxicology Letters, Amsterdam, v.127, p.19-28, 2002. 
D’MELLO, J. P. F.; MACDONALD, A. M. C. Mycotoxins. Animal Feed Science And Technology, Amsterdam, v.69, p.155-166, 1997.

D’MELLO, J. P. F; PLACINTA, C. M.; MACDONALD, A. M. C. Fusarium mycotoxins: a review of global implications for animal health, welfare and productivity. Animal Feed Science And Technology, Amsterdam, v.80, p.183-205, 1999.

DESAI, K.; SULLARDS, M. C.; ALLEGOOD, J.; WANG, E.; SCHMELZ, E. M.; HARTL, M.; HUMPF, H.; LIOTTA, D. C.; PENG, Q.; MERRILL JR., A. H. Fumonisins and fumonisins analogs as inhibitors of ceramide synthase and inducers of apoptosis. Biochimica et Biophysica Acta, Amsterdam, v.1585, p.188-192, 2002.

DOWSWELL, C.R.;PALIWAL, R. L.; CANTRELL, R.P.Maize in the third world. Oxford: Wesrview Press, 1996. p.1-34.

DRAGAN, Y. P.; BIDLACK, W. R.; COHEN, S. M.; GOLDSWORTHY, T. L.; HARD, G. C.; HOWARD, P. C.; RILEY, R. T.; VOSS, K. A. Implications os apoptosis for toxicity, carcinogenicity, and risk assessment: Fumonisin $\mathrm{B}_{1}$ as an example. Toxicological Sciences, Orlando, v.61, p.6-17, 2001.

DUARTE, J. O. Embrapa Milho e Sorgo: sistema de produção 1: mercado e comercialização. Disponível em: < http://www.cnpms.embrapa.br>. Acesso em: 04 jun. 2003.

ENONGENE, E. N.; SHARMA, R. P.; BHANDARI, N.; VOSS, K. A.; RILEY, R. T. Disruption of sphingolipid metabolism in small intestines, liver and kidney of mice dosed subcutaneously with fumonisin $\mathrm{B}_{1}$. Food and Chemical Toxicology, Oxford, v.38, p.793-799, 2000.

ENONGENE, E. N.; SHARMA, R. P.; BHANDARI, N.; MILLER, J. D.; MEREDITH, F. I.; VOSS, K. A.; RILEY, R. T. Persistence and reversibility of the elevation in free sphingoid bases induced by fumonisin inhibition of ceramide synthase. Toxicological Sciences, Orlando, v.67, p.173-181, 2002.

FERRANTE, M.C.; MELI, R.; RASO, G.M.; ESPOSITO, E.; SEVERINO, L.; DI CARLO, G.; LUCISANO, A. Effect of fumonisin $\mathrm{B}_{1}$ on structure and function of macrophage plasma membrane. Toxicology Letters, Amsterdam, v.129, p.181-187, 2002.

FINK-GREMMELS, J. H. Micotoxins: Their implications for human and animal health. Veterinary Quarterly, The Hague, v.21, n.4, p.115-120, oct.1999.

GALVANO, F.; RUSSO, A.; CARDILE, V.; GALVANO, G.; VANELLA, A.; RENIS, M. DNA damage em human fibroblasts exposed to fumonisin $\mathrm{B}_{1}$. Food and Chemical Toxicology, Oxford, v.40, p.25-31, 2002.

GELDERBLOM, W. C. A.; JASKIEWICZ, K.; MARASAS, W. F. O.; THIEL, P. G.; HORAK, R. M.; VLEGGAAR, R.;
KRIEK, N. P. Fumonisins: novel mycotoxins with cancerpromoting activity produced by Fusarium moniliforme. Applied and Environmental Microbiology, Washington, v.54, n.7, p.1806-1811, 1988.

GELDERBLOM, W. C. A.; ABEL, S.; SMUTS, C. M.; MARNEWICK, J.; MARASAS, W. F. O.; LEMMER, E. R.; RAMLJAK, D. Fumonisin-induced hepatocarcinogenesis: mechanisms related to cancer initiation and promotion. Environmental Health Perspectives, Research Triangle Park, v.109, n.2, p.291-300, 2001.

HASCHEK, W. M.; GUMPRECHT, L. A.; SMITH, G.; TUMBLESON, M. E.; CONSTABLE, P. D. Fumonisin toxicosis in swine: An overview of porcine pulmonary edema and current perspectives. Environmental Health Perspectives, Research Triangle Park, v.109, n.2, p.251257, may 2001.

HE, Q.; BHANDARI, N.; SHARMA, R. P. Fumonisin B alters sphingolipid metabolism and tumor necrosis factor að expression in heart and lung of mice. Life Sciences, Elmsford, v.71, p. 2015-2023, 2002.

HE, Q.; RILEY, R. T.; SHARMA, R. P. Fumonisin-induced tumor necrosis factor-að expression in a porcine kidney cell line is independent of sphingoid base accumulation induced by ceramide synthase inhibition. Toxicology and Applied Pharmacology, San Diego, v.174, p.69-77, 2001.

HIROOKA, E. Y.; YAMAGUCHI, M. M.; AOYAMA, S.; SUGIURA, Y.; UENO, Y. The natural occurrence of fumonisins in Brazilian corn kernels. Food Additives and Contaminants, London, v.13, n.2, p.173-183, 1996.

HUSSEIN, H. S.; BRASSEL, J. M. Toxicity, metabolism, and impact of mycotoxins on humans and animals. Toxicology, Limerick, v.167, p.101-134, 2001.

IPCS - International Programme on Chemical Safety [2000] Fumonisin B1. Environmental Health Criteria 219, World Health Organization, Finland, 150 p.

KIM, M. S.; LEE, D. Y.; WANG, T.; SCHROEDER, J. J. Fumonisin $\mathrm{B}_{1}$ induces apoptosis in LLC-PK 1 renal epithelial cells via a sphinganine- and calmodulindependent pathway. Toxicology and Applied Pharmacology, San Diego, v.176, p.118-126, 2001.

MARASAS, W. F. O. Discovery and occurrence of the fumonisins: a historical perspective. Environmental Health Perspectives, Research Triangle Park, v.109, n.2, p.239243, may 2001.

Melo Filho, G. A.; Richietti, A. Aspectos socioeconômicos da cultura do milho. In: EMBRAPA. Centro de Pesquisa Agropecuarias do Oeste. Milho: informações tecnicas. Dourados, 1997. p.13-38. (EMBRAPA-CPAO. Circular Técnica, 5). 
MERRIL JR., A. H.; SCHEMELZ, E. M.; DILLEHAY, D. L.; SPIEGEL, S.; SHAYMAN, J. A.; SCHROEDER, J. J.; RILEY, R. T.; VOSS, K. A.; WANG. E. Sphingolipids: the enigmatic lipid class: biochemistry, physiology, and pathophysiology. Toxicology and Applied Pharmacology, San Diego, v.142, p.208-225, 1997.

MERRILL JR., A. H.; SULLARDS, C.; WANG, E.; VOSS, K. A.; RILEY, R. T. Sphingolipid metabolism: roles in signal transduction and disruption by fumonisins. Environmental Health Perspectives, Research Triangle Park, v.109, n.2, p.283-289, may 2001.

MOBIO, T. A.; ANANE, R.; BAUDRIMONT, I.; CARRATU, M. R.; SHIER, W. T.; DANO-DJEDJE, S.; UENO, Y., CREPPY, E. E. Epigenetic properties of fumonisin $\mathrm{B}_{1}$ : cell cycle arrest and DNA base modification in $\mathrm{C}_{6}$ glioma cells. Toxicology and Applied Pharmacology, San Diego, v.164, p.91-96, 2000.

MUNKVOLD, G. P.; DESJARDINS, A. E. Fumonisins in maize: can we reduce their occurrence? Plant Disease, Saint Paul, v.81, n.6, p.556-565, jun.1997.

MUSSER, S. M.; PLATTNER, R. D. Fumonisin composition in cultures of Fusarium moniliforme, Fusarium proliferatum and Fusarium nygamai. Journal of Agricultural and Food Chemistry, Easton, v.45, n.4, p.1169-1173, 1997.

NORRED, W. P.; VOSS, K. A. Toxicity and role of fumonisins in animal diseases and human esophageal cancer. Journal of Food Protection, Des Moines, v.57, p.522-527, 1994.

NORRED, W. P.; VOSS, K. A.; RILEY, R. T.; PLATTNER, R. D. Fumonisin toxicity and metabolism studies at the USDA. In: JACKSON, L.; DEVRIES, J. W.; BULLERMAN, L. B. Fumonisins in food. New York: Plenum Press, 1996. 399p.

PEDROSA, A. V. B.; DEZEN, R. B. O milho: características do mercado e perspectivas. Preços Agrícolas, Piracicaba, v.55, p.1-4, 1991.

PELAGALLI, A.; BELISARIO, M. A.; SQUILLACIOTI, C.; MORTE, R. D.; D'ANGELO, D.; TAFURI, S.; LUCISANO, A.; STAIANO, N. The mycotoxin fumonisin $\mathrm{B}_{1}$ inhibits integrin-mediated cell-matrix adhesion. Biochimie, Paris, v.81, p.1003-1008, 1999.

PETSKA, J. J.; ABOUZEID, M. N.; SUTIKNO. Immunological assays for mycotoxin detection. Food Technology, Chicago, v.49, n.2, p.120-128, 1995.

PLACINTA, C. M.; D'MELLO, J. P. F; MACDONALD, A. M. C. A review of cereal grains and animal feed with Fusarium mycotoxins. Animal Feed Science And Technology, Amsterdam, v.78, p.21-37, 1999.
RILEY, R. T.; AN, N. H.; SHOWKER, J. L.; YOO, H. S.; NORRED, W. P.; CHAMBERLAIN, W. J.; WANG, E.; MERRIL JR., A. H.; MOTELIN, G.; BEASLEY, V. R.; HASCHEK, W. M. Alteration of tissue and serum sphinganine to sphingosine ratio: an early biomarker of exposure to fumonisin-containing feeds in pigs. Toxicology and Applied Pharmacology, San Diego, v.118, p.105-112, 1993.

RILEY, R. T.; ENONGENE, E.; VOSS, K. A.; NORRED, W. P.; MEREDITH, F. I.; SHARMA, R. P.; SPITSBERGEN, J.; WILLIANS, D. E.; CARLSON, D. B.; MERRILL JR., A. H. Sphingolipid perturbations as mechanisms for fumonisin carcinogenesis. Environmental Health Perspectives, Research Triangle Park, v.109, n.2, p.301-308, may 2001.

SAUNDERS, D. S.; MEREDITH, F. I.; VOSS, K. A. Control of fumonisin: effects of processing. Environmental Health Perspectives, Research Triangle Park, v.109, n.2, p.333336, may 2001.

SCHMELZ, E. M.; DOMBRINK-KURTZMAN, M. A.; ROBERTS, P. C.; KOZUTSUMI, Y.; KAWASAKI, T.; MERRIL JR., A. H. Induction of apoptosis by fumonisin $\mathrm{B}_{1}$ in HT29 cells is mediated by the accumulation of endogenous free sphingoid bases. Toxicology and Applied Pharmacology, San Diego, v.148, p.252-260, 1998.

SHEPARD, G. S.; VAN DER WESTHUIZEN, L.; THIEL, P. G.; GELDERBLOM, W. C. A.; MARASAS, W. F. O.; VAN SCHALKWYK, D. J. Disruption of sphingolipid metabolism in non-human primates consuming diets of fumonisin-containing Fusarium moniliforme culture material. Toxicon, Elmsford, v.34, n.5, p.527-534, 1996.

SOLFRIZZO, M.; AVANTAGGIATO, G.; VISCONTI, A. Rapid method to determine sphinganine/sphingosine in human and animal urine as a biomarker for fumonisin exposure. Journal of Chromatography B, Amsterdam, v.692, p.87-93, 1997.

SOLFRIZZO, M.; CARRATU, M. R.; AVANTAGGIATO, G.; GALVANO, F.; PIETRI, A.; VISCONTI, A. Ineffectivenes of activated carbon in reducing the alteration of sphingolipid metabolism in rats exposed to fumonisin-contaminated diets. Food and Chemical Toxicology, Oxford, v.39, p.507-511, 2001.

STEYN, P. S. Mycotoxins, general view, chemistry and structure. Toxicology Letters, Amsterdam, v.82/83, p.843851, 1995.

SYDENHAM. E. W.; SHEPARD, G. S. Chomatographic and allied methods of analysis for selected mycotoxins. In GILBERT, J. Progress in food contaminat analysis. London: Backie Academic \& Professional, 1996. p.65-146. 
TURNER, P. C.; NIKIEMA, P.; WILD, C. P. Fumonisin contamination of food: progress in development of biomarkers to better assess human health risks. Mutation Research, Amsterdam, v.443, p.81-93, 1999.

UENO, Y.; AOYAMA, S.; SUGIURA, Y.; WANG, D. S.; LEE, U. S.; HIROOKA, E. Y.; HARA, S.; KARKI, T.; CHEN, G.; YU, S. Z. A limited survey of fumonisins in corn and corn-based products in Asian countries. Mycotoxin Research, Amsterdam, v.9, p.27-34, 1993.

UENO, Y.; IIJIMA, K.; WANG, S. D.; SUGIURA, Y.; SEKIJIMA, M.; TANAKA, T.; CHEN, C.; YU, S. Z. Fumonisins as a possible contribuitory risk factor for primary liver cancer: a 3-year study of corn harvested in Haimen, China, by HPLC and ELISA. Food and Chemical Toxicology, Oxford, v.35, p.1143-1150, 1997.

VAN DER WESTHUIZEN, L.; BROWN, N. L.; MARASAS, W. F. O.; SWANEVELDER, S.; SHEPARD, G. S. Sphinganine/Sphingosine ratio in plasma and urine as a possible biomarker for fumonisin exposure in humans in rural areas of Africa. Food and Chemical Toxicology, Oxford, v.37, p.1153-1158, 1999.

VAN DER WESTHUIZEN, L.; SHEPARD, G. S.; VAN SCHALKWYK, D. J. The effect of a single gavage dose of fumonisin $\mathrm{B}_{1}$ on the sphinganine and sphingosine levels in vervet monkeys. Toxicon, Elmsford, v.39, p.273-281, 2001a.

VAN DER WESTHUIZEN, L.; SHEPARD, G. S.; VAN SCHALKWYK, D. J. The effect of repeated doses of fumonisin $\mathrm{B}_{1}$ on the sphinganine and sphingosine levels in vervet monkeys. Toxicon, Elmsford, v.39, p.969-972, 2001 b.
VISCONTI, A.; BOENKE, A; DOKO, M. B.; SOLFRIZZO, M.; PASCALE, M. Occurrence of fumonisin in Europe and BCR: measurements and testing projects. Natural Toxins, New York, v.3, n.4, p.269-274, 1995.

VOSS, K. A.; HOWARD, P. C.; RILEY, R. T.; SHARMA, R. P.; BUCCI, T. J.; LORENTZEN, R. J. Carcinogenicity and mechanism of action of fumonisin $\mathrm{B}_{1}$ : a mycotoxin produced by Fusarium moniliforme ( $F$. verticillioides). Cancer Detection and Prevention, New York, v.26, p.1-9, 2002.

VOSS, K. A.; RILEY, R. T.; NORRED, W. P.; BACON, C. W.; MEREDITH, F. I.; HOWARD, P. C.; PLATTNER, R. D.; COLLINS, T. F. X.; HANSEN, D. K.; PORTER, J. K. An overview of rodent toxicities: liver and kidney effects of fumonisins and Fusarium moniliforme. Environmental Health Perspectives, Research Triangle Park, v.109, n.2, p.259-266, may 2001.

WANG, E.; NORRED, W. P.; BACON, R. T.; RILEY, R. T.; MERRIL JR.; A. H. Inhibition of sphingolipid biosynthesis by fumonisins: implications for diseases associated with Fusarium moniliforme. Journal of Biological Chemistry, Bethesda, v.266, p.14486-144990, 1991.

WORLD HEALTH ORGANIZATION. International Programme on Chemical Safety. Fumonisin $\mathrm{B}_{1}$. Geneva, 2000. (Environmental Health Criteria Monographs, 219).

YIN, J. J.; SMITH, M. J.; EPPLEY, R. M.; PAGE, S. W.; SPHON, J. A. Effects of fumonisin $\mathrm{B}_{1}$ on lipid peroxidation in membranes. Biochimica et Biophysica Acta, Amsterdam, v.1371, p.134-142, 1998. 
